
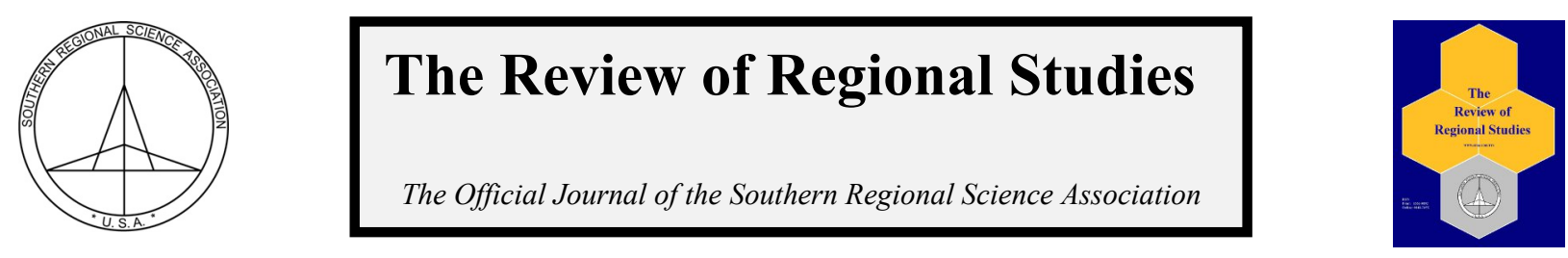

\title{
Are There Key Sectors? An Appraisal Using Applied General Equilibrium*
}

\author{
M. Alejandro Cardenete ${ }^{\mathrm{a}}$, M. Carmen Lima ${ }^{\mathrm{b}}$, and Ferran Sancho ${ }^{\mathrm{c}}$ \\ ${ }^{a}$ Department of Economics, Universidad Loyola Andalucia, Spain \\ ${ }^{b}$ Department of Economics, Universidad Pablo de Olavide, Spain \\ ${ }^{c}$ Department of Economics, Universidad Autónoma de Barcelona, Spain
}

\begin{abstract}
An extension of the hypothetical extraction method to a general equilibrium setting is considered. This has the advantage of re-interpreting output changes as efficiency gains or losses, which may be of use in identifying "key" sectors in an interconnected economy. The categorization may be relevant for the evaluation of intersectoral synergies and for improving policy planning and orienting economic strategy. We argue that the standard measures based on gross outputs may not capture all of the relevant impacts and this is so because of some self-imposed modeling and accounting limitations. An economy-wide Computable General Equilibrium (CGE) approach provides a modeling platform that overcomes these limitations since it offers (i) a more comprehensive measure of linkages and (ii) an alternative way of accounting for linkages' relevance that is in closer accordance with the standard statistical magnitudes used in national or regional accounts.
\end{abstract}

Keywords: key sectors, hypothetical extraction, applied general equilibrium, economic impulse, sectoral efficiency JEL Codes: C63, C68, D58

\section{INTRODUCTION}

In defining economic policies and designing planning strategies a key piece of information should be the foreseeable extent of impact of a given action. To elicit such an impact an accounting of the ensuing costs and benefits is needed. From the viewpoint of costs, we can simplify and identify total monetary cost as an investment baseline. With a given cost the balance of the alternative policies will rest with their accrued potential benefits. In a networked economy such benefits will depend on in what economic sector the policy is eventually implemented. But sectors are intrinsically different and the way they translate a spending impulse into economic benefits will depend also on their interdependencies and mutual links. Thus less integrated sectors should give rise to fewer benefits since they tend to multiply less of their impulses into more activity, and the opposite should be the case for highly integrated sectors. From the perspective of the government, for instance, it is relevant to know how a spending policy may translate into economic impulse, and deciding where to apply public resources may well turn out to be a non-neutral, and therefore strategic, decision (Devarajan, Swaroop, and Zou, 1993). Since an economy is a set of interlocked components, these

\footnotetext{
${ }^{*}$ Cardenete and Sancho are grateful for support from projects MICINN-ECO 2009-11857 and SGR 2009-578. Lima is grateful for support from projects MICINN-ECO 2009-13357 and SEJ-4546 from the Andalusian regional government.

Cardenete is Professor of Economics at the Universidad Loyola Andalucía, Seville, Spain. Lima is Associate Professor of Economics at the Universidad Pablo de Olavide, Seville, Spain. Sancho is Professor of Economics at the Universidad Autónoma de Barcelona, Barcelona, Spain. Corresponding Author: M.A. Cardenete E-mail: macardenete@uloyola.es
}

C) Southern Regional Science Association 2014.

ISSN 1553-0892, 0048-749X (online)

www.srsa.org/rrs 
considerations lead to the crucial point of how to measure the role of these components, or sectors, in the functioning of the overall economy.

Despite some consensus on how to approach this question, an answer has not been easy to come by. This is probably because the preferred methodological platform, general equilibrium analysis in its broadest sense, is amenable to quite a few different behavioral postulates. The option that appears to be typically chosen, the interindustry model, has underlying assumptions that are clearly too restrictive, behaviorally speaking, that give rise to highly biased appraisals. Under the interindustry approach, the direction of change following an exogenous demand injection is always positive for all sectors. All sectors are 'winners', even if it is with different intensities. But as we will discuss later, when more comprehensive and realistic restrictions are taken into account, sectors can be 'winners' or 'losers' in terms of the policy-induced adjustments.

This paper sets out to examine the reasonableness of the key sector concept in its present and generally accepted customary sense, and its possible implications for policy design. We have organized the paper as follows. In Section I we introduce the state of the key sector literature from a modeling perspective and discuss some of the relevant issues in regard to policy analysis. Section II develops the rationale for implementing extractions in a CGE setup. In Section III we annotate the main traits of the CGE model we use. Section IV shows some numerical illustrations of sector extractions for a simple reference economy. Section V concludes with some reflections on the approach and its validity and usefulness as a tool for policy evaluation.

\section{A REVIEW OF THE ISSUES}

Two approaches have been commonly used in the literature for measuring the role that a sector plays within the economy. The classical one involves measuring multiplier effects based on estimated square multiplier matrices (Rasmussen, 1956; Chenery and Watanabe 1958; and Hirschman, 1958). Cells in columns and rows of these matrices provide information on the bilateral linkage between each possible pair of sectors. By aggregating and composing the entries in columns (or rows, for that matter) a hierarchy of sectors can be established according to the impact that an inflow in a given sector will transfer, on average, to the companion sectors through the mechanisms of mutual economic interdependencies. Sectors that have higher than average multipliers are usually identified as key sectors. They would exert the highest impact on the generation of new gross output. These values correspond to so-called pull effects. ${ }^{1}$

The second main approach goes beyond multiplier effects and aims at gauging the role of a sector by way of simulating its absence. This is basis of the hypothetical extraction method (HEM) initially proposed independently by Paelinck, De Caevel and Degueldre (1965) and Miller (1966) and developed further by Strassert (1968), among others. The differences in gross output between the economies with and without the sector are taken as a measure of the importance of the extracted sector. The goal of the method is therefore to measure the economic costs in terms of lost output should a productive sector cease to relate with the remaining sectors of the economy. The hypothetical elimination of a sector translates now, unlike the output expansion in the multiplier approach, into a general contraction in terms of output. Miller and

\footnotetext{
${ }^{1}$ We will not pay attention here to push or forward-linkage effects that are computed from matrix row sums since they are not accepted in the current literature. This notwithstanding, it is worth remembering that Hirschman's (1958) classical definition of a key sector requires both above-average backward and forward effects.
}

(C) Southern Regional Science Association 2014. 
Lahr (2001) provide the most comprehensive review of the hypothetical extraction method and its variations within the interindustry model while other recent applications can be found in Sanchez-Chóliz and Duarte (2003), Cai and Leung (2004), and Dietzenbacher and Lahr (2013), who present interesting discussions on other extractions in input-output (I-O) models.

These two standard approaches, even if used independently in most practical applications, have recently been proved to be theoretically connected by Temurshoev and Oosterhaven (2010). Guerra (2013), in turn, proposes a hybrid model that combines both standard methods but allows for a much clearer decomposition of the multiplier effects. These common methodologies, however, are somewhat restrictive since they closely follow the tenets of the linear interindustry model. The interindustry model is based on Leontief's pioneer contribution (Leontief, 1951) and developed from the flow information contained in input-output tables produced by Statistical Offices. An input-output table can be seen as a snapshot of an economy in equilibrium, with detailed information on intermediate transactions, value-added and final demand. From the observed equilibrium snapshot a model can be implemented under some behavioral assumptions that relate to technology, primary factors' use, and final demand. Typically, the technology assumptions reflect a very specific set of production functions with constant returns to scale and zero elasticity of substitution among inputs. While constant returns to scale is a commonly accepted empirical assumption at the level of aggregation of these models (Kehoe, Polo, and Sancho, 1995), the zero elasticity of substitution is a more debatable postulate that has been defended on grounds of solution tractability and operational simplicity. With the use of these assumptions, the interindustry model adopts a linear structure that captures the relationship between final demand and total production in an economy. The fact that final demand is taken to be as external to the modeling system constitutes a serious limitation (Pyatt and Round, 1979). In other words, the model does not account for a fully endogenous budget constraint for households. In the interindustry model, factors' income does not flow back to factors' owners and the flow of income is not closed. A solution for 'closing' the flow of income is the Social Accounting Matrix, SAM for short (Stone, 1962, 1981).

Some of the limitations of the interindustry linear model were correctly pointed out by Diamond $(1974,1976)$ in his work dealing with development issues. When final demand is left unexplained, its influence in measuring key sectors is bound to be neglected. A derived problem arises from the selection of the weighting metric that translates "keyness" into policy appraisals. Depending on the selected preference function of the policy maker, results can be non-unique, even distinct. Diamond tackles these problems closing the input-output model with an embedded demand subsystem and using alternative coefficient vectors, hence different metrics, to convert the extended multiplier matrix into policy-oriented valuations.

There are, however, additional and substantial income and expenditure links beyond those of the demand subsystem that the interindustry approach also misses and that are relevant for policy analysis and evaluation. As an accounting tool, a Social Accounting Matrix is comprehensive since all income and spending, up to a degree of institutional disaggregation, is fully accounted for. This modeling extension uses additional and more encompassing endogeneity, making the accounts for households and primary factors to behave endogenously in the income determination process. These SAM extensions, however valuable, are confined to be within the linear paradigm. Under the classical multiplier approach, the additional endogeneity yields multiplier matrices that collect a higher level of economic interactions. Alternatively, one could adapt the extraction method to the SAM model. This is what Cardenete and Sancho 
(2006a) propose. They implement a very standard linear SAM model from which production sectors are sequentially extracted and gross equilibrium output is recomputed and compared with benchmark output. This straightforward extraction extension changes not only output levels (as it should be expected given the enlarged endogeneity included in a SAM) but also and more interesting the rank ordering of the output effects when compared with those of the interindustry setup. Similarly, using a set of CGE simulations Cardenete and Sancho (2012) also show that multiplier matrices are critically dependent upon resource constraints and general equilibrium adjustments. The systematically positive multiplier matrices in interindustry analysis cease to hold, and negatively valued multipliers become, all of a sudden, possible. These are limited but nonetheless suggestive empirical evidence that the missing income-expenditure links do matter, and should therefore be incorporated, for a broader assessment of policies. In contrast, Miller and Lahr (2001) provide empirical evidence that the type of extraction does not seem to matter that much in terms of sectoral ordering as long as we restrict linkage computations to the interindustry setup.

Thus if external to production linkages matter then it is only natural that they should also be examined using the computable general equilibrium (CGE) approach. A few clear advantages of CGE models, besides being well rooted in sound microeconomic theory, is that they depart from the linearity assumptions of the interindustry and SAM models, include supply constraints, and encompass a more detailed accounting structure that yields results that easily and nicely fit within the National Income and Products Accounts categories. In general terms, a large number of output evaluations of sectoral linkages have been based or computed from units of gross output. For comparison purposes, it should also be interesting to use a measure of net output like gross domestic product (GDP) ${ }^{2}$ that nets out the double-counting of production that accumulates within gross output and that provides a cleaner metric in welfare terms. ${ }^{3}$ It is also worth remembering that the technology assumptions governing linear models give rise to a version of the so-called classical dichotomy (Oosterhaven, 1996) whereby equilibrium quantities and prices are independently determined of each other. This is in sharp contrast with the case of general equilibrium models of the Walrasian type where equilibrium is achieved at the same time in quantities and prices. Hence changes in the GDP metric for net output will capture induced and simultaneous effects on both prices and quantities. Notice that there is no equivalent metric to GDP in terms of gross production for, again, it would include double-counting from intermediate costs.

\section{THE HYPOTHETICAL EXTRACTION METHOD}

The extraction of a sector from the economy has to be seen as a virtual experiment which provides quantitative information on the role exerted by that sector within the whole economy. As we have already commented, when the critical issue is economic interdependency, the models that pick up and symbolize that characteristic are interindustry, SAM and CGE models. They are

\footnotetext{
${ }^{2}$ Linear models can, however, compute changes in value-added from changes in gross output for given prices. Employment effects can be calculated too and they depend on overall output effects within the interindustry model. See Groenewold, Hagger, and Madden (1993) for an exhaustive employment analysis. The reshuffling of intermediate production, being irrelevant for the statistics on net production, get transmitted, in a second round of general equilibrium effects, into changes in value added or into domestic/imported input share.

${ }^{3}$ Gross production includes intermediate and final production. To avoid double counting, intermediate production should not be reported when measuring final or net production. See Oosterhaven and Stelder (2002) and Sancho (2013) for a discussion of this issue within the interindustry model.
}

(c) Southern Regional Science Association 2014. 
all built upon the idea that sectors influence each other in direct (via first-round bilateral dependencies) and indirect (via second-round general equilibrium) ways.

The simplest way to start is by using, as a template, a simple, constant-returns-to-scale (CRS), interindustry economy described by a matrix of technical coefficients $\mathbf{A}$ and an exogenous vector of final demand $\mathbf{f}$. Let $\mathbf{g}$ stand for the vector of gross output and let us partition all matrix and vectors using the convention that the index 1 represents the sector ${ }^{4}$ that hypothetically ceases to relate with the rest of the economy and the indices $2,3, \ldots, n$ represent the rest of the economy's sectors. Then the quantity interindustry equation can be expressed as:

$$
\mathbf{g}=\mathbf{A g}+\mathbf{f}=\left[\begin{array}{cccc}
a_{11} & a_{12} & \cdots & a_{1 n} \\
a_{21} & a_{22} & \cdots & a_{2 n} \\
\vdots & \vdots & \ddots & \vdots \\
a_{n 1} & a_{n 2} & \cdots & a_{n n}
\end{array}\right] \cdot\left[\begin{array}{c}
g_{1} \\
g_{2} \\
\vdots \\
g_{n}
\end{array}\right]+\left[\begin{array}{c}
f_{1} \\
f_{2} \\
\vdots \\
f_{n}
\end{array}\right]
$$

Suppose now that sector 1 is 'hypothetically extracted' in the sense that it neither sells goods to nor purchases inputs from the 'remaining' sectors $2,3, \ldots, n$. Sector 1 still operates but it is 'isolated' from the rest of the economy. ${ }^{5}$ Under this assumption, to satisfy the final demand levels in vector $\mathbf{f}$ will require a gross output level $\overline{\mathbf{g}}$ such as:

$$
\overline{\mathbf{g}}=\overline{\mathbf{A}}_{(-1)} \overline{\mathbf{g}}+\mathbf{f}=\left[\begin{array}{cccc}
a_{11} & 0 & \cdots & 0 \\
0 & a_{22} & \cdots & a_{2 n} \\
\vdots & \vdots & \ddots & \vdots \\
0 & a_{n 2} & \cdots & a_{n n}
\end{array}\right] \cdot\left[\begin{array}{c}
\bar{g}_{1} \\
\bar{g}_{2} \\
\vdots \\
\bar{g}_{n}
\end{array}\right]+\left[\begin{array}{c}
f_{1} \\
f_{2} \\
\vdots \\
f_{n}
\end{array}\right]
$$

where $\overline{\mathbf{A}}_{(-1)}$ is the matrix of technical coefficients with all interindustry linkages to sector 1 extracted. Solving for the reduced forms of Equations (1) and (2) and using $\Delta \mathbf{g}_{(-1)}$ to denote differential output after extracting sector 1 we find:

$$
\Delta \mathbf{g}_{(-1)}=\mathbf{g}-\overline{\mathbf{g}}=\left((\mathbf{I}-\mathbf{A})^{-1}-\left(\mathbf{I}-\overline{\mathbf{A}}_{(-1)}\right)^{-1}\right) \cdot \mathbf{f}
$$

The vector difference $\Delta \mathbf{g}_{(-1)}$ in Equation (3) indicates the sectoral output losses when sector 1 stops relating to the rest of economic sectors. Under a fix price assumption and a unit normalization the scalar $\mathbf{i} \cdot \Delta \mathbf{g}_{(-1)}$, where $\mathbf{i}$ is a summation vector of ones, represent total gross output loss should sector 1 be extracted from the economy. Since we can exchange the role of sectors (sector 2 being 'extracted', then 3, 4, etc.) a sequential chain of extractions $\overline{\mathbf{A}}_{(-1)}, \overline{\mathbf{A}}_{(-2)}, \overline{\mathbf{A}}_{(-3)}, \ldots, \overline{\mathbf{A}}_{(-n)}$ of all economic sectors from the initial matrix $\mathbf{A}$ can be visualized. It is clear then that the larger the aggregate output loss associated to a given sector $j$ being 'extracted', that is $\mathbf{i} \cdot \Delta \mathbf{g}_{(-j)}$, the more relevant that sector is to the networked economy. It is in

\footnotetext{
${ }^{4}$ Or a block of sectors. Also, if regional or spatial data are available, the reinterpretation to key locations is immediate. The modeling facility, however, should be different so as to incorporate spatial considerations like the difference between regional and national pricing levels. We focus here on national sectors because of data availability.

${ }^{5}$ Isolation is the most common option for sector extractions. There are however other options for extractions that reflect different technological restrictions (Miller and Lahr, 2001).
}

(C) Southern Regional Science Association 2014. 
this sense that a sector can be termed as being a "key" sector and that the omitted or "missing" links are indeed significant (see Miller and Lahr, 2001, for this interpretation).

Efficiency gains are routinely explored in an ad-hoc and simple manner by way of simulating reductions in input coefficients and recomputing new equilibrium values under the assumed reduction. Partial extractions are possible and can be modulated by way of controlling the reduction parameters as Guerra and Sancho (2010) formally show. It is therefore in this sense that a different interpretation of the consequences of an extraction can be provided in terms of efficiency gains measured by the hypothetically lost output.

Notice that since in equation (3) the vector $\mathbf{f}$ remains constant, the vector difference $\mathbf{g}-\overline{\mathbf{g}}$ shows to what extent the extraction of the sector decreases the overall input levels needed to continue satisfying final demand $\mathbf{f}$. This diminished demand for intermediate inputs is therefore an indication of the underlying productive efficiency of sector 1. Clearly then, the larger the output loss in the standard interpretation the larger the efficiency gain in our interpretation. The advantage of this alternative explanation is that the notion of efficiency gain can be straightforwardly extended to modeling options quite different from the explicit linear one present in expressions (1) and (2), in particular it can be used to capture efficiency gains not only from an output perspective but also from the point of view of price adjustments.

Indeed, the effect of the extraction is measured, in the standard approach, only against the initial baseline gross output g. From a standard welfare perspective, however, an interesting measure to evaluate the impact of the extraction could be one based on net or final output or, even more convenient, on a GDP metric as mentioned before. ${ }^{6}$ A quick look at expressions (1) and (2) tells us that since final demand would be constant in the I-O setting, there would be no real effect on final domestic output after performing an extraction. This is not very satisfactory since then all we are measuring using (3) are adjustments in intermediate production, a magnitude that is of little interest in the National Accounts, as well as in terms of policy evaluation regarding welfare effects. Another shortcoming of the standard formulation is that it is not clear how the remaining sectors 2,3 , etc. obtain their needed inputs if the extracted sector, say sector 1 , is not supplying them. Or where the extracted sector 1 obtains its necessary inputs if it is not buying them from 2, 3, etc. This issue is explained away by appealing to the external sector as a perfect substitute provider. ${ }^{7}$

From a circular flow of income perspective, however, the results of an extraction should be calculated taking account of all the standing economic connections, considering adjustments both in quantities and prices, and in particular final demand $\mathbf{f}$ should be considered as endogenous, rather than fixed, to capture the effect of income adjustments.

This is the natural setup for a computable general equilibrium model to be of use, and what we propose in this paper. When the technology matrix $\mathbf{A}$ is replaced, even if hypothetically, by a matrix $\mathbf{A}_{(-j)}$ a chain reaction of allocation adjustments in quantities and prices will take place in order to achieve a new (hypothetical) equilibrium. When this chain reaction is studied under an empirically calibrated general equilibrium model, we can estimate the induced policy effects and possibly identify what sectors, if extracted, would promote the most change. For an economy

\footnotetext{
${ }^{6}$ See Ten Raa and Mohnen (2002) for a theoretical discussion of using a GDP metric for capturing factor productivities.

${ }^{7}$ Notice then that we would jump from the standard zero substitution elasticities of the interindustry model to infinite trade substitution elasticity.
}

(C) Southern Regional Science Association 2014. 
with $n$ production sectors this requires $n$ equilibrium computations, once for each hypothetically extracted sector and matrix $\mathbf{A}_{(-j)}$.

\section{BASIC ASPECTS OF THE CGE MODEL}

We use a very standard CGE model of a national economy. A description of the essential properties of this type of models and their usefulness for the analysis of economy-wide issues can be found in the seminal contributions of Dervis, de Melo, and Robinson (1982) and Shoven and Whalley (1984), while Ginsburgh and Keyzer (2002), Kehoe, Srinivisan, and Whalley (2005), Hosoe, Gasawa, and Hashimoto (2010), Burfisher (2011), Cardenete, Guerra, and Sancho (2012) are quite complete, up-to-date reviews of the state of the art.

The CGE model shares the basic principles of the Walrasian paradigm. The model rests on a set of assumptions - on functional forms, consumers and firms' behavior, and others - that are standard in the literature. The model is also enlarged with agents and sectors that are not usually present in the theoretical literature but are needed in an empirically-oriented model, such as the public and foreign sectors. It contemplates 35 distinct economic sectors that reflect the level of aggregation in the Social Accounting Matrix database that gives numerical support.

One of the essential pieces in the simulations is the productive nesting since we will consider different scenarios for the substitution elasticity. Productive sectors operate under CRS nested technologies governed by constant elasticity of substitution (CES) functions. In the first level of the nest, total output $\mathrm{g}_{j}$ is obtained combining domestic $g_{j}^{D}$ and imported $g_{j}^{M}$ outputs using an Armington (1969) specification for those sectors with trade (greater than zero substitution elasticity $\sigma_{j}^{G}$ ). In the second level of the nested technology, domestic output is produced combining value-added $v_{j}$ and intermediate inputs $a_{i j}$ in fixed proportions (zerosubstitution elasticity). In the third level, finally, value added is generated using a technology that combines labor $l_{j}$ and capital $k_{j}$ (with greater than zero elasticity of substitution $\sigma_{j}^{l k}$ ). The nesting looks like: ${ }^{8}$

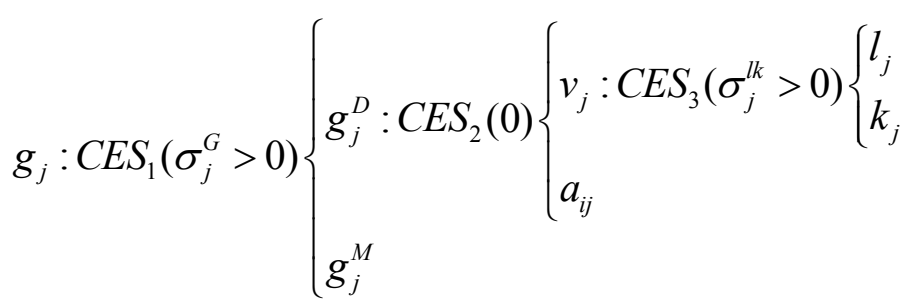

All goods, services and primary factors are traded in competitive markets. Thus prices satisfy an average cost pricing rule. There are aggregate resource constraints for labor and capital but these homogeneous factors are mobile among sectors and fully utilized in equilibrium.

Note that regarding factor adjustments, the extracted sector is isolated from the rest but still active, hence still demanding factors for its isolated production needs. But it would now need less of those factors because of the partial shutting down of its activities. If a sector were to be fully extracted, i.e., eliminated from the productive side of the economy, then its demand for primary factors would vanish. The sector would not be productively active anymore. Hence,

\footnotetext{
${ }^{8}$ Notice that all imports are consolidated into a unique account and we do not distinguish them by origin (European Union and rest of the world) since this distinction does not bear on the question at hand.
} 
labor and capital would have to reallocate, flowing elsewhere, as a consequence of the extraction and the subsequent market adjustments. The CGE framework is able to capture these factors' reallocation effects, in an explicit and measurable way. When a sector is extracted, in whichever way, its demand for factors will change, but if factors are not sector specific, they will be made available to the market. They are still in the economy and they are still being supplied by their owners (consumers) seeking a retribution for their rental. Facing the changing factors' demand landscapes, the economy will adjust via new wages and capital rental rates. Primary factors reallocate, hypothetically of course, after each extraction, showing how the economy would adjust after a sector ceased to relate to the rest of productive sectors in the economy, all other relationships standing. Needless to say this is not the only possible scenario. Other modeling approaches are indeed possible regarding, for instance, labor market behavior. Factors could be left somewhat unused (i.e., unemployment and/or idle capital) or be considered partly sector specific (i.e., the unskilled and hardly mobile labor of some sectors).

There is a representative consumer that demands final consumption facing price vectors $\mathbf{p}$ for goods and $\mathbf{w}$ for primary factors under a budget constraint that includes factor income, government transfers $T$ and external lump-sum transfers. Households' incomes are in turn subject to a linear income-tax schedule. Consumption includes consumption today and consumption tomorrow, as a proxy for savings within the model. The consumer adjusts consumption following a simple Cobb-Douglas aggregator, with demand represented by vector $\mathbf{c}(\mathbf{p}, \mathbf{w}, T)$. We use this formulation for two reasons. One is simplicity and the fact that the reference simulation below uses unitary elasticities throughout. The second reason is that we want to focus on the effects of technological variability on the production side of the economy. The detection of key sectors rests after all on the mutual productive connections among sectors. To this effect we do not consider any alternatives in the demand side of the economy, and we keep the Cobb-Douglas demand system as a fixed characteristic of the model.

The government collects an indirect tax on transactions $T_{g}(\mathbf{p}, \mathbf{w}, \mathbf{g})$ and a tax on income and on capital earnings $T_{\mathbf{k}}(\mathbf{p}, \mathbf{w}, \mathbf{g})$. These receipts are used to finance the purchase of public consumption $\mathbf{b}(\mathbf{p}, \mathbf{w}, \mathbf{g})$ for goods and services. Tax receipts also allow the government to finance its social policies which are measured here by the provision of social transfers $T$ to the private representative agent. The public deficit $\delta$ can be considered endogenous or exogenous depending on the selected closure rule. Here we keep the size of the government fixed in terms of its expenditures to control that its activities are not unduly masking the productive sectoral interplay, and thus $\delta$ is endogenously determined.

Investment is savings driven. Savings, in turn, are determined by prices for both goods $\mathbf{p}$ and for primary factors $\mathbf{w}$ as well as by activity levels $\mathbf{g}$. Thus investment demand can be represented by a function $\mathbf{y}(\mathbf{p}, \mathbf{w}, \mathbf{g})$. Total final demand adds up private consumption $\mathbf{c}$, public consumption $\mathbf{b}$, investment $\mathbf{y}$ and exports $\overline{\mathbf{x}}$ yielding aggregate final demand that we represent by:

$$
\mathbf{f}(\mathbf{p}, \mathbf{w}, T)=\mathbf{c}(\mathbf{p}, \mathbf{w}, T)+\mathbf{b}(\mathbf{p}, \mathbf{w}, \mathbf{g})+\mathbf{y}(\mathbf{p}, \mathbf{w}, \mathbf{g})+\overline{\mathbf{x}}
$$

Simply stated, an equilibrium for an economy characterized by a technology $\left(\mathbf{A}, \sigma^{G}, \sigma^{l k}\right)$ and a fixed level of exports $\overline{\mathbf{x}}$ is a gross output allocation $\mathbf{g}^{*}$, a vector of prices for goods and factors $\left(\mathbf{p}^{*}, \mathbf{w}^{*}\right)$, and a level of government transfers $T^{*}$, such that all markets clear, the government expenditure function 'clears' all taxes paid by private agents, the aggregate savings function clear with the level of investment demand and given the CRS assumption prices for

(C) Southern Regional Science Association 2014. 
goods and services follow the average cost rule ensuring zero after tax profits for all firms. On the production side, gross output covers intermediate and final demands and the following supply-demand condition for goods will be satisfied in equilibrium:

$$
\mathbf{g}^{*}=\mathbf{A} \cdot \mathbf{g}^{*}+\mathbf{f}\left(\mathbf{p}^{*}, \mathbf{w}^{*}, T^{*}\right)
$$

Because of the CRT technology assumption, factors' demands are given by the conditional demand functions for labor and capital, $L^{d}$ and $K^{d}$. The following conditions will hold in equilibrium between demand and supply of factors ${ }^{9}$ :

$$
\begin{aligned}
& L^{d}\left(\mathbf{p}^{*}, \mathbf{w}^{*}, \mathbf{g}^{*}\right)=L^{s} \\
& K^{d}\left(\mathbf{p}^{*}, \mathbf{w}^{*}, \mathbf{g}^{*}\right)=K^{s}
\end{aligned}
$$

Government activities will necessarily satisfy the budget constraint for public expenditures and public income:

$$
T^{*}+\mathbf{p} \cdot \mathbf{b}\left(\mathbf{p}^{*}, \mathbf{w}^{*}, \mathbf{g}^{*}\right)+\delta=T_{g}\left(\mathbf{p}^{*}, \mathbf{w}^{*}, \mathbf{g}^{*}\right)+T_{k}\left(\mathbf{p}^{*}, \mathbf{w}^{*}, \mathbf{g}^{*}\right)
$$

Finally, the zero profit condition under CRT requires:

$$
\mathbf{p}^{*}=\mathbf{p}^{*} \cdot \mathbf{A}+p_{v}\left(\mathbf{w}^{*}\right) \cdot \mathbf{v}\left(\mathbf{w}^{*}\right)
$$

where $p_{v}(\mathbf{w})$ is the efficient price index for value-added and $\mathbf{v}(\mathbf{w})$ is a vector of unitary valueadded demand. The simplified model represented by expressions (6) to (9) comprises $2 n+3$ equations and $2 n+3$ variables but because of Walras's Law one equation is redundant. Choosing a price as numéraire solves the problem and a solution with relative prices can be obtained using computing techniques.

The model represents a national economy and therefore the macroeconomic condition on the equality of total savings (private, public and external) and investment must hold in the equilibrium. ${ }^{10}$ Notice that the different origins of savings are determined by the same price variables as private consumption and by total activity levels so that the model has well-defined, endogenously driven investment function $\mathbf{y}(\mathbf{p}, \mathbf{w}, \mathbf{g})$.

The CGE model computes the equilibrium effects of the hypothetical economy $\left(\mathbf{A}_{(-j)}, \sigma^{G}, \sigma^{l k}\right)$ resulting from sequentially extracting each of the productive sectors, i.e., $j=1$, $2, \ldots, n$. For each of these hypothetical economies, we compute the equilibrium effects on the GDP metric that can be ascribed to the extraction of each sector. Notice that the comparative statics exercise involved in each model run after the extraction implies the substitution of the given technology matrix $A$ for the simulated matrices $\mathbf{A}_{(-j)}$, all else (parameters, coefficients, behavioral relationships and so on) being kept equal. Thus the new equilibrium states provide the overall effects of the extraction, understood here as the substitution of matrix $\mathbf{A}$ by matrix $\mathbf{A}_{(-j)}$, conditional to maintaining the rest of the structure that represents the economy.

\footnotetext{
${ }^{9}$ This assumption could be relaxed to allow for endogenous unemployment. Since the aim of our exercise is methodological rather than descriptive we prefer not to introduce any further distorting factor in the analysis.

${ }^{10}$ This is the so-called neoclassical closure rule, which is the most commonly used in CGE modeling of national economies. Other macro closure rules are however possible, such as the Keynesian rule or Johansen's rule. These may be more appropriate in subnational or regional models where investment need not be equal to savings ex-ante. See Polo and Valle (2008) for a discussion of closure rules in a regional model.
}

(C) Southern Regional Science Association 2014. 


\section{DATA AND SIMULATION RESULTS}

The CGE model is calibrated from a Social Accounting Matrix (SAM) assembled by Cardenete and Sancho (2006b) using official input-output data, tax surveys from the Treasury, and complementary information from the national accounts. We have adapted the structure of this SAM to simplify and rearrange government activities. Using the apportioning methodology proposed by Pyatt (1985), we have reduced all government and fiscal tax categories to just one account. Using this procedure, a unique government account collects all expenditure and tax receipts in such a way that only two tax categories remain, i.e. an indirect tax and an income tax.

We perform the following hypothetical experiment: each sector is extracted and the counterfactual equilibrium recomputed. This involves, within the given model structure, a general reallocation of resources with simultaneous adjustments in quantities and prices. We then measure changes in aggregate GDP and compare them to baseline GDP, all magnitudes expressed in terms of the same numéraire - the wage rate. The changes in GDP can be seen as the welfare gain (or loss) of extracting a sector after all general equilibrium adjustments in prices and quantities, however long they end up taking, have occurred. Since time does not play any role in the model, the reported effects should not be interpreted within any given time framework. Results just indicate the configuration of alternative equilibria once all markets have had a chance to adjust. This central experiment is undertaken for a configuration of substitution elasticities that correspond to the Cobb-Douglas variety. In order to assess sensitivity, we then complement the experiment by repeating the computations for a range of substitution elasticities that depart from the unitary ones. We allow first for technologies with a higher degree of substitution among primary inputs and then for technologies with a higher degree of complementarity. Upper and lower bound values for the elasticities have been chosen that are somewhat reasonable given the available econometrics estimates. In the Appendix, Tables 1-3 show a summary of the results for this interval evaluation.

A first result is that there are sectors that win and sectors that lose-unlike the systematic gross output losses reported in the linear interindustry or SAM models by the extraction method. When there is a full reallocation of resources, or at least full in terms of the more complex structure of a CGE model, and both output and price effects are allowed to take place, then the combined effect may yield an increase in aggregate GDP as a result of the extraction, or not. If we look at Table 1, for instance, the extraction of sector 1 ends up having a positive effect on the economy's overall GDP ( 1.75 percent) whereas extracting sector 2 yields a fall, even if small, in GDP. In contrast, gross output falls (1.91 percent) when we extract sector 1. From the somewhat narrower perspective of linear models the conclusion would be that a fall in gross output takes place and that would have a negative connotation. However, final output as measured by GDP in fact increases - a positive implication that would be masked should we have looked only at gross output measures. With full and simultaneous price and quantity reallocation all possibilities seem to arise. See for instance the extraction of sector 14, where the consequence would be that both final and gross output aggregate measures increase; and should sector 25 be extracted, then we would observe a decrease in GDP and an increase in gross output; or how the extraction of sector 2 would produce a negative impact in both aggregate indicators.

Table 2 illustrates a recomputation of all equilibria under a higher degree of technological substitution. We choose a common Armington elasticity of $\sigma^{G}=3$ for all sectors with trade in the database and $\sigma^{l k}=2$ as the labor-capital substitution elasticity, values that are empirically 
reasonable, yet they posit somehow flatter isoquants in the first and second level of the nested production functions. Table 3 repeats calculations but now for isoquants with higher complementarities. For this case we select elasticities of substitution of $\sigma^{G}=\sigma^{l k}=0.5$, again within the range of reasonable, though low, empirical values.

Table 1. Extraction effects: Cobb-Douglas case

\begin{tabular}{|c|c|c|}
\hline Sector & $\%$ change in GDP & $\%$ change in gross output \\
\hline 1. Agriculture, stockbreeding, hunting, fishing and forestry. & 1.75 & -1.91 \\
\hline 2. Coal & -0.07 & -0.08 \\
\hline 3. Petroleum & 0.73 & 0.03 \\
\hline 4. Metallic products manufacture & 0.07 & 0.03 \\
\hline 5. Non-metallic mineral products industry & 0.19 & -0.06 \\
\hline 6. Petroleum refine and nuclear fuel processing & 1.43 & -0.01 \\
\hline 7. Electricity & 1.42 & -0.46 \\
\hline 8. Gas Distribution & 0.13 & 0.03 \\
\hline 9. Water Distribution & 0.06 & -0.04 \\
\hline 10. Food, beverage and tobacco industry & 2.28 & -3.00 \\
\hline 11. Textiles and leathers & 1.06 & -0.51 \\
\hline 12. Wood & 0.21 & -0.00 \\
\hline 13. Paper industry; publishing, graphic arts and reproduction & 0.62 & 0.13 \\
\hline 14.Chemical Products & 1.23 & 0.42 \\
\hline 15. Rubber processing and plastic materials industry & 0.47 & -0.00 \\
\hline 16. Cement and glass & 0.72 & -0.29 \\
\hline 17. Metallurgy & 1.35 & 0.15 \\
\hline 18. Machinery & 1.09 & 0.59 \\
\hline $\begin{array}{l}\text { 19. Electric, electronic and optical materials and equipment } \\
\text { industry }\end{array}$ & 0.30 & 0.22 \\
\hline 20. Vehicles & 1.44 & -0.72 \\
\hline 21. Furniture & 0.73 & -0.11 \\
\hline 22. Recycling Services & 0.05 & 0.01 \\
\hline 23. Construction & 1.82 & -0.20 \\
\hline 24. Commerce & 2.07 & -0.77 \\
\hline 25. Hotels and Restaurants & -0.05 & 2.00 \\
\hline 26. Transport & 2.31 & -1.88 \\
\hline 27. Financial Services & 1.01 & -0.08 \\
\hline 28. Other Services & 0.53 & -1.63 \\
\hline 29. Education & 0.28 & 0.05 \\
\hline 30. Non Commercial Services & 0.25 & 0.12 \\
\hline 31. Personal Services & 0.46 & 0.14 \\
\hline 32. Public Services & 0.50 & -0.18 \\
\hline 33. Non Commercial Education & 0.13 & -0.01 \\
\hline 34. Health Services & 0.53 & 0.04 \\
\hline 35. Cultural Services & 0.11 & -0.00 \\
\hline
\end{tabular}

Source: own elaboration 
Table 2. Extraction effects: High substitution case.

\begin{tabular}{|c|c|c|}
\hline Sector & $\%$ change in GDP & $\%$ change in gross output \\
\hline 1. Agriculture, stockbreeding, hunting, fishing and forestry & 0.78 & -2.23 \\
\hline 2. Coal & -0.02 & -0.08 \\
\hline 3. Petroleum & 0.90 & -0.37 \\
\hline 4. Metallic products manufacture & 0.07 & 0.03 \\
\hline 5. Non-metallic mineral products industry & 0.15 & -0.11 \\
\hline 6. Petroleum refine and nuclear fuel processing & 1.57 & -0.81 \\
\hline 7. Electricity & 1.08 & -0.52 \\
\hline 8. Gas Distribution & 0.11 & 0.03 \\
\hline 9. Water Distribution & 0.06 & -0.03 \\
\hline 10. Food, beverage and tobacco industry & 1.78 & -4.07 \\
\hline 11. Textiles and leathers & 1.01 & -0.86 \\
\hline 12. Wood & 0.21 & -0.06 \\
\hline $\begin{array}{l}\text { 13. Paper industry; publishing, graphic arts and } \\
\text { reproduction }\end{array}$ & 0.65 & 0.03 \\
\hline 14.Chemical Products & 1.31 & -0.26 \\
\hline 15. Rubber processing and plastic materials industry & 0.52 & -0.50 \\
\hline 16 Cement and glass & 0.63 & -0.62 \\
\hline 17. Metallurgy & 1.49 & -0.80 \\
\hline 18. Machinery & 1.37 & 0.16 \\
\hline $\begin{array}{l}\text { 19. Electric, electronic and optical materials and } \\
\text { equipment industry }\end{array}$ & 0.43 & 0.29 \\
\hline 20. Vehicles & 1.66 & -3.16 \\
\hline 21. Furniture & 0.62 & -0.25 \\
\hline 22. Recycing Services & 0.04 & 0.01 \\
\hline 23. Construction & 1.67 & -0.22 \\
\hline 24. Commerce & 1.96 & -1.08 \\
\hline 25. Hotels and Restaurants & 0.51 & 2.02 \\
\hline 26. Transport & 2.03 & -2.17 \\
\hline 27. Financial Services & 1.12 & -0.09 \\
\hline 28. Other Services & 1.18 & -1.77 \\
\hline 29. Education & 0.20 & 0.05 \\
\hline 30. Non Commercial Services & 0.23 & 0.13 \\
\hline 31. Personal Services & 0.40 & 0.20 \\
\hline 32. Public Services & 0.43 & -0.19 \\
\hline 33. Non Commercial Education & 0.10 & -0.01 \\
\hline 34. Health Services & 0.40 & 0.04 \\
\hline 35. Cultural Services & 0.08 & 0.00 \\
\hline
\end{tabular}

Armington elasticity $=3$

$V A$ elasticity $=2$

Source: own elaboration 
Table 3. Extraction effects: Low substitution case.

\begin{tabular}{|c|c|c|}
\hline Sector & $\%$ change in GDP & $\%$ change in gross output \\
\hline 1. Agriculture, stockbreeding, hunting, fishing and forestry & 4.04 & -1.85 \\
\hline 2. Coal & -0.20 & -0.08 \\
\hline 3. Petroleum & 0.35 & 0.11 \\
\hline 4. Metallic products manufacture & 0.07 & 0.04 \\
\hline 5. Non-metallic mineral products industry & 0.28 & -0.05 \\
\hline 6. Petroleum refine and nuclear fuel processing & 1.09 & 0.22 \\
\hline 7. Electricity & 2.23 & -0.43 \\
\hline 8. Gas Distribution & 0.18 & 0.04 \\
\hline 9. Water Distribution & 0.04 & -0.04 \\
\hline 10. Food, beverage and tobacco industry & 3.55 & -2.79 \\
\hline 11. Textiles and leathers & 1.40 & -0.46 \\
\hline 12. Wood & 0.24 & 0.01 \\
\hline $\begin{array}{l}\text { 13. Paper industry; publishing, graphic arts and } \\
\text { reproduction }\end{array}$ & 0.61 & 0.14 \\
\hline 14.Chemical Products & 1.16 & 0.50 \\
\hline 15. Rubber processing and plastic materials industry & 0.32 & 0.12 \\
\hline 16. Cement and glass & 0.90 & -0.20 \\
\hline 17. Metallurgy & 1.22 & 0.34 \\
\hline 18. Machinery & 0.74 & 0.55 \\
\hline $\begin{array}{l}\text { 19. Electric, electronic and optical materials and } \\
\text { equipment industry }\end{array}$ & 0.25 & 0.16 \\
\hline 20. Vehicles & 1.20 & -0.26 \\
\hline 21. Furniture & 1.00 & -0.15 \\
\hline 22. Recycling Services & 1.00 & -0.11 \\
\hline 23. Construction & 2.16 & -0.19 \\
\hline 24. Commerce & 2.29 & -0.68 \\
\hline 25. Hotels and Restaurants & -1.41 & 1.96 \\
\hline 26. Transport & 2.95 & -1.80 \\
\hline 27. Financial Services & 0.78 & -0.08 \\
\hline 28. Other Services & -0.94 & -1.62 \\
\hline 29. Education & 0.46 & 0.06 \\
\hline 30. Non Commercial Services & 0.29 & 0.12 \\
\hline 31. Personal Services & 0.65 & 0.11 \\
\hline 32. Public Services & 0.68 & -0.18 \\
\hline 33. Non Commercial Education & 0.19 & -0.01 \\
\hline 34. Health Services & 0.84 & 0.05 \\
\hline 35. Cultural Services & 0.18 & 0.00 \\
\hline
\end{tabular}

Armington elasticity $=0.5$

$V A$ elasticity $=0.5$

Source: own elaboration

A comparison of the GDP data points out that more (or less) substitution possibilities does not necessarily translate into a smaller (respectively, larger) effect. It is true that in most cases (about two thirds of them) higher elasticities of substitution give rise to smaller impacts in term of percentage change, but not in all cases (about a third). Similarly, but on the opposite end, lower substitution elasticities correspond to larger percentage effects in many but not all cases. 
As for gross output effects, the higher (the lower) the elasticity of substitution, the larger (the smaller) the percentage drop in output in all but a few cases.

The simulation outcomes reported here point out that technology seems to matter, and substantially, when evaluating the economic weight of linkages induced by networked sectors. Linear models assume a very specific set of technology relationships governing sectors (e.g., zero-substitution elasticities in intermediate inputs and primary factors) and in doing so they condition their results in a very specific direction. CGE models, in contrast, incorporate strong nonlinearities as a result of some of the technical coefficients being price-dependent, thus endogenously variable. In addition to income effects, which are a distinctive property of linear models, fully integrated general equilibrium models also contemplate substitution effects that work through changes in relative prices. When quantities and prices are simultaneously determined in all markets, linearity is lost and the web of reciprocal effects is considerably more complex. As a further difference with standard I-O and SAM linear models, CGE models include aggregate supply constraints, such as fixed amounts of labor and capital, which are not typically present in the linear models. This helps to explain too why the extraction of a sector may yield a positive or negative effect in terms of final output. For instance labor and/or capital will be reallocated by the market adjustment process among productive sectors and depending on the strength of the reallocation results can go in either direction.

In spite of the fact that the CGE framework is able to capture a wider range of effects, the CGE "black box" model effect is still at play. Factors' reallocations, for instance, can be calculated and compared between equilibria but the ability to discern underlying trends is not so easily achieved. Extensive and detailed calculations would be needed to ascertain if the reallocation of factors is consistently affecting some specific sectors. If this were the case, some hidden but active circuits of influence of an structural category could be revealed.

To complicate things further, and as mentioned before, many other modeling options regulating the primary factors markets are of course possible, such as introducing labor unemployment or capital excess capacity, or allowing some factors to be, fully or partly, sector specific. Results from the hypothetical extractions would correspondingly vary reflecting these different economic structures. Which modeling option is eventually chosen should be the result of a comprehensive analysis on the empirical plausibility of the economic structures. For instance, in advanced economies fuller factor flexibility and intersectoral mobility should be expected whereas in developing economies some factor rigidities would surely be more prevalent and active.

As long as we believe that some degree of technological substitution is present in an actual, it becomes of paramount importance to have as good an empirical estimate as possible, since whether a sector turns out to be a 'key' sector (or not) seems to depend not only on how that sector inter-relates to other sectors in the network of sectors but also on the way the output of a sector intra-relates to its inputs and their substitution possibilities.

\section{CONCLUDING REMARKS}

We have explored the role played by some technology relationships and output-incomedemand links in defining the extent a given economic sector may end up being considered a "key" sector. We have argued that an economywide CGE model may provide some help in obtaining more in-depth insights on this issue since this type of model allows for a more 
comprehensive representation of the economic reality in terms of actual linkages. To this effect the hypothetical extraction methodology has been extended to a CGE model under a scenario of sector isolation. An advantage of CGE models is that they easily provide indicators of impact on final production that capture both price and quantity adjustments, as well as the standard gross output measures typical of linear models. In a CGE, model resource reallocation can yield a positive or negative impact, depending on the combined price and quantity general equilibrium effects. It is because of the structure of linear models that extractions will unequivocally produce a negative impact on gross output. Finally, we observe that substitution possibilities in production are a significant parameter in order to elicit extraction effects. If so, a careful estimation (or at the very least an educated choice based on a wide literature search) of appropriate Armington and labor-capital substitution elasticities is called for. There seems to be, anyhow, more empirical consensus on sensible values of the labor-capital substitution than on Armington elasticities but a flow of recent estimates are providing good empirical foundations that fortunately can be borrowed and fruitfully used by CGE practitioners ${ }^{11}$.

A strategy for a more accurate evaluation of substitution effects in terms of policy appraisal would call for models with a sounder empirical foundation. This requires at least two pieces of data that are typical and quite essential in CGE modeling. One is the availability of SAM databases. Unfortunately National Statistical Offices do not produce SAMs in a timely manner, or not at all, and the work of assembling them rests ultimately on researchers. Another one is the availability of country specific and sector specific substitution elasticities. Many of the econometrics estimates correspond to levels of aggregation or types of goods that are not the required ones in CGE modeling. Thus adjustments have to be made for models to be operational and tractable. These limitations may call into question the credibility of the simulation results that CGE models produce and, in particular, the credibility of their policy recommendations. We refer to Kehoe, Polo, and Sancho (1995) for a first discussion on the empirical validation of CGE models in terms of their predictive ability. They find that CGE models do fairly well in matching simulation results with actual observations. In a conceptual discussion this was previously suggested, but not tested, by one of the leaders in the CGE field (Whalley, 1987) when he argued that CGE models embody extensive information on the complexity of the underlying economic structure. If CGE models tend to work fairly well their simulation results could provide valuable information to policy makers.

The structure of the economy in terms of substitution possibilities seems to be a driving force as far as identifying 'key' sectors is concerned. But are there key sectors? The answer seems to be 'no' if by such we understand a sector that, in the tradition of the standard key sector literature, unequivocally pushes the economy ahead, and produces above average pull effects, when facing an external injection. This consideration may have relevant implications for policy design since, contrary to the usual key sector presumptions, an injection may not have the expected positive effect dictated by the traditional multiplier and HEM approaches. Demanddriven policies by governments that aim at activating the economy may not work as expected. For instance, investing in bailing out an industry because of its presumed 'key' role in the economy will involve drawing resources from elsewhere, and the use of those resources is not costless. Reshuffling resources will produce distortions on others parts of the economy that might offset the alleged benefits of the expenditure policy.

\footnotetext{
${ }^{11}$ Roland-Holst and Reinert (1992) and Balistreri and McDaniel (2003) estimate Armington elasticities. Chirinko (2002) and Klump, McAdam, and Willman (2007) present substitution elasticities for primary inputs.
}

(C) Southern Regional Science Association 2014. 
The fact that quite often governments' spending policies rely heavily on the recommendations of traditional key sector analysis suggests they should therefore be carefully reconsidered. Other significant conditioning factors, such as technological interactions and supply constraints, are at play affecting results, as our simple CGE exercises point out. Even when all these features are taken into account and controlled for, the 'key' policy issue regarding possible government decisions still remains. Sectors can of course be catalogued from high to low response in terms of the GDP metric but this will always be conditional to the implemented assumptions describing the economy. In some sense, the classification becomes multifaceted and akin to some type of hedonic parameterization property, rather than one dimensional as in the traditional literature.

Our simulations here should not be strictly read in descriptive or statistical terms. Rather, they are just a first example to signal that other approaches to determining key sectors are possible and, perhaps, necessary as well. Much more work needs to be done, of course, in particular to provide sounder explanations of why sectors become 'key' under a CGE approach, especially since the nonlinearities of CGE models make their results less transparent and less easy to interpret than those of the linear models. If labor and capital intersectoral adjustments turn out to be significant in driving results, then more work in modeling their influence is certainly needed. This would allow us to ascertain whether some structural role is at work but hidden from the initial scrutiny. A possible new line of research would be to define, and calculate, the employment effects associated with an extraction. This would require a different modeling of the labor market capable of measuring employment reallocation effects while differentiating intrasectoral (internal) and intersectoral (outside) effects.

\section{REFERENCES}

Armington, Paul. S. (1969) "A Theory of Demand for Products Distinguished by Place of Production," International Monetary Fund Staff Papers, 16, 159-178.

Balistreri, Eduard and Christine McDaniel. (2003) "A Review of Armington Trade Substitution Elasticities," Integration and Trade, 7(18), 161-173.

Burfisher, Mary E. (2011) Introduction to Computable General Equilibrium Models. Cambridge University Press: Cambridge, UK.

Cai, Junning and Pinsung Leung. (2004) "Linkage Measures: a Revisit and a Suggested Alternative," Economic Systems Research, 16, 65-85.

Cardenete, M. Alejandro, Ana I. Guerra, and Ferran Sancho. (2012) Applied General Equilibrium: An Introduction. Springer: New York.

Cardenete, M. Alejandro and Ferran Sancho. (2006a) "Missing Links in Key Sector Analysis," Economic Systems Research, 18, 319-326.

(2006b) "Elaboración de una Matriz de Contabilidad Social a través del Método de Entropía Cruzada," Estadística Española, 48(161), 67-100.

. (2012) "The Role of Supply Constraints in Multiplier Analysis," Economic Systems Research, 24, 21-34.

Chenery, Hollis B. and Tsunehiko Watanabe. (1958) "International Comparisons of the Structure of Production," Econometrica, 26, 487-521. 
Chirinko, Robert. (2002) "Corporate Taxation, Capital Formation and the Substitution Elasticity Between Labor and Capital," National Tax Journal, 55, 339-355.

Dervis, Kemal, Jaime de Melo, and Sherman Robinson. (1982) General Equilibrium Models for Development Policy. Cambridge University Press: Cambridge, UK.

Devarajan, Shantayanan, Vinaya Swaroop, and Heng-fu Zou. (1993) "What do Government Buy? The Composition of Public Spending and Economic Performance," World Bank Working Paper WPS 1082.

Diamond, Jack. (1974) "The Analysis of Structural Constraints in Developing Economies: a Case Study," Oxford Bulletin of Economics and Statistics, 36, 95-118.

. (1976) "Key Sectors in Some Undeveloped Countries: a Comment," Kyklos, 29, 762764.

Dietzenbacher, Erik and Michael Lahr. (2013) "Expanding Extractions," Economic Systems Research, 25, 369-389.

Ginsburgh, Victor and Michiel Keyzer. (2002) The Structure of Applied General Equilibrium Models. MIT Press: Cambridge, MA.

Groenewold, Nicolaas, Alfred H. Hagger, and John R. Madden. (1993) "Measuring Industry Importance: an Australian Application," Annals of Regional Science, 27(2), 175-182.

Guerra, Ana I. (2013). "Merging the Hypothetical Extraction Method and the Classical Multiplier Approach: A Hybrid Possibility for Identifying Key Distributive Sectors," Working paper, Universidad de Granada.

Guerra, Ana I. and Ferran Sancho. (2010) "Measuring Energy Linkages with the Hypothetical Extraction Method," Energy Economics, 32, 831-837.

Hirschman, Albert O. (1958) The Strategy of Economic Development. Yale University Press: New Haven, CT.

Hosoe, Nobuhiro, Kenji Gasawa, and Hirofumi Hashimoto. (2010) Textbook of Computable General Equilibrium Modeling: Programming and Simulations. Palgrave MacMillan: London.

Kehoe, Timothy, Clemente Polo, and Ferran Sancho. (1995) "An Evaluation of the Performance of an Applied General Equilibrium Model of the Spanish Economy," Economic Theory, 1995, 6(1), 115-141.

Kehoe, Timothy, Thirukidikaval N.Srinivisan, and John Whalley. (2005) Frontiers in Applied General Equilibrium Modeling. Cambridge University Press: New York.

Klump, Rainer, Peter McAdam, and Alpo Willman. (2007) "Factor Substitution and Factoraugmenting Technical Progress in the United States: A Normalized Supply-side System Approach," Review of Economics and Statistics, 89, 183-192.

Leontief, Wassily. (1951). Input-Output Economics, $2^{\text {nd }}$ ed., Oxford University Press: New York.

Miller, Ronald E. (1966), "Interregional Feedback Effects in Input-Output Models: Some Preliminary Results," Papers in Regional Science, 17, 105-125. 
Miller, Ronald. E. and Michael Lahr. (2001) “A Taxonomy of Extractions," in Michael L. Lahr and Ronald E. Miller, eds., Regional Science Perspectives in Economic Analysis: A Festschrift in Memory of Benjamin H. Stevens. Elsevier Science: Amsterdam, pp. 407411.

Oosterhaven, Jan. (1996) "Leontief versus Ghoshian Price and Quantity Models," Southern Economic Journal, 62, 750-59.

Oosterhaven, Jan and Dirk Stelder. (2002) "Net Multipliers Avoid Exagerating Impacts: With a Bi-regional Illustration for the Dutch Transportation Sector," Journal of Regional Science, 42, 533-543.

Paelinck, Jean, Jean De Caevel, and Joseph Degueldre. (1965) “Analyse Quantitative de Certaines Phenomenes du Developpment Regional Polarise: Essai de Simulation Statique d'iteraires de Propogation," in Biblioteque de l'Institut de Science Economique, No. 7, Problemes de Conversion Economique: Analyses Theoretiques et Etudes Appliquees. M.Th. Genin: Paris, pp. 341-387.

Polo, Clemente and Elisabeth Valle. (2008) "A General Equilibrium Assessment of the Impact of a Fall in Tourism under Alternative Closure Rules: The Case of the Balearic Islands," International Regional Science Review, 31, 3-34.

Pyatt, Graham. (1985) "Commodity Balances and National Accounts: a Sam Perspective," Review of Income and Wealth, 31, 155-169.

Pyatt, Graham and Jeffery Round. (1979) "Accounting and Fixprice Multipliers in a Social Accounting Matrix Framework," Economic Journal, 89(356): 850-873.

Rasmussen, Paul N. (1956) Studies in Inter-Sectoral Relations. Einar Harks: Copenhagen.

Roland-Holst, David W. and Knut Reinert. (1992) "Armington Elasticities for U.S. Manufacturing Sectors," Journal of Policy Modelling, 14, 631-639.

Sánchez-Chóliz, Julio and Rosa Duarte. (2003) "Production Chains and Linkage Indicators," Economic Systems Research, 15, 481-494.

Sancho, Ferran. (2013) "Some Conceptual Difficulties of Net Multipliers," Annals of Regional Science, 51, 537-552.

Shoven, John B. and John Whalley. (1984) "Applied General Equilibrium Analysis of Taxation and Trade," Journal of Economic Literature, 22, 1007-105.

Stone, Richard. (1962) Programme for Growth: A Social Accounting Matrix for 1960. Chapman and Hall: London.

- (1981) Aspects of Economic and Social Accounting, Monograph 126. Librairie Droze: Geneva.

Strassert, Gûnter. (1968) “Zur Bestimmung Stretegischer Sektoren mit Hilfe von Input-OutputModellen," Jahrbücher für Nationalökonomie und Statistik, 182, 211-215.

ten Raa, Thijs and Pierre Mohnen. (2002) "Neoclassical Growth Accounting and Frontier Analysis: A Synthesis," Journal of Productivity Analysis, 18, 111-128.

Temurshoev, Umed and Jan Oosterhaven. (2010) “On Input-Output Linkage Measures," Working Papers in Input-Output Economics, WPIOX 10-02.

(C) Southern Regional Science Association 2014. 
Whalley, John. (1987) "Operationalizing Walras: Experience with Recent Applied General Equilibrium Tax Models," in Truman Bewley, ed., Advances in Econometrics, Volume 2. Cambridge University Press: Cambridge, UK, pp. 231 